\title{
Analysis of amino nitrogen content affecting fermentation and wine quality
}

\author{
Kállay, M. \& Sárdy Nyitrainé, D. \\ Corvinus University of Budapest, Faculty of Food Science, Department of Oenology
}

Summary: A suitable amount of nitrogen source is needed for the optimal process of alcoholic fermentation. The professional literature mentions the complexity of nitrogen compounds exploitable for yeast-plants as an assimilable or immediately assumable nitrogen source. Former experiments proved that in case of low nitrogen concentration, yeast-plants produced a bigger quantity of hydrogen sulphide. According to the findings above, it is not indifferent when and how we complement the nitrogen content of the must. The aim of our present work was to elaborate such a quick, easily applicable method that can be used for routinish measurements in the viticultural practice.

Key words: amino nitrogen, formol titration, spectrophotometrical measurement

\section{Introduction}

Compounds with nitrogen content can be found in musts in organic and inorganic forms. The inorganic nitrogen component is the ammonium cation. Among organic compounds, there are amido compounds, amino acids, polypeptides, peptones and proteins in musts (Kállay, 1998).

A suitable amount of nitrogen source is needed for the optimal process of alcoholic fermentation. The professional literature mentions the complexity of nitrogen compounds exploitable for yeast-plants as an assimilable or immediately assumable nitrogen source. The immediately assumable nitrogen forms (IAN) of the must are as follow:

- the inorganic salts of the $\mathrm{NH}_{4}{ }^{+}$-cation

- free amino acids except proline

- in the lack of the items above, with the help of peptidase enzyme bound in the cells, wine yeast can exploit also the protein nitrogen.

In a former work of ours, we already described the nitrogen utilization of the fermentation process. (Kállay et. al., 2004.) At an early stage of fermentation, yeast consumes almost only the inorganic form appearing in the must and

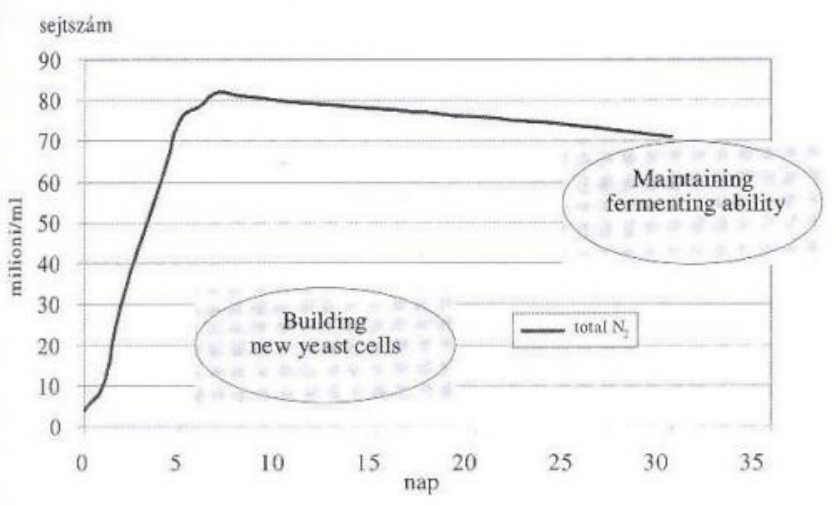

Figure 1: Nitrogen utilization at different stages of fermentation uses it for cell building. In the course of the second stage of fermentation, the assimilation of free amino acids takes place. (Figure 1).

The assimilable nitrogen that musts contain in the form of $\mathrm{NH}_{4}{ }^{+}$has a direct effect on the maximum fermentation speed attainable at the beginning of fermentation, which can be traced by the daily sugar decrease or the quantity of alocohol generated, however, it does not have any impact on the further process of fermentation (Figure 2).

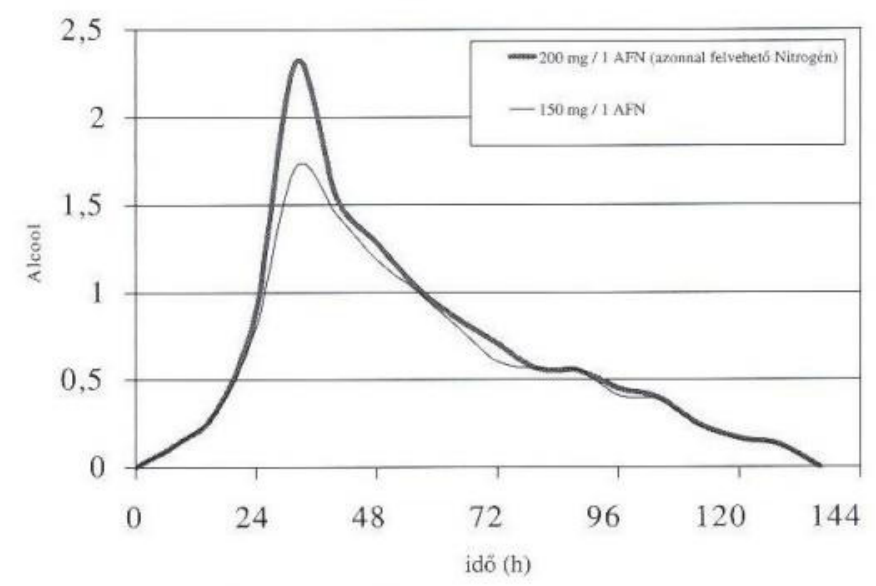

Figure 2: The effect of the initial $\mathrm{N}$-concentration on the maximum fermenting ability of yeast

Former experiments proved that in case of low nitrogen concentration, yeast-plants produced a bigger quantity of hydrogen sulphide. (Vos \& Grag, 1979; Henschke \& Jiranek, 1993)

It is in connection with the synthesis of sulphureous amino acids (methionine, cysteine) and the S-adenosyl-methionine (SAM) acting as a methyl donor, for which yeasts get the sulphide group by reducing the sulphate and sulphite content of must. The sulphate reception and reduction is regulated by 
methionine and the SAM at several points. The decrease of their concentration within the cell results in intensifying the sulphate reduction. Due to the lack of nitrogen, the precursors of sulphureous amino acids, which the generating sulphide group could be built in, are not available. Hydrogen sulphide, generated as the interim product of the sulphate reduction gets into the must and it causes some serious fermentation failure (Figure 3).

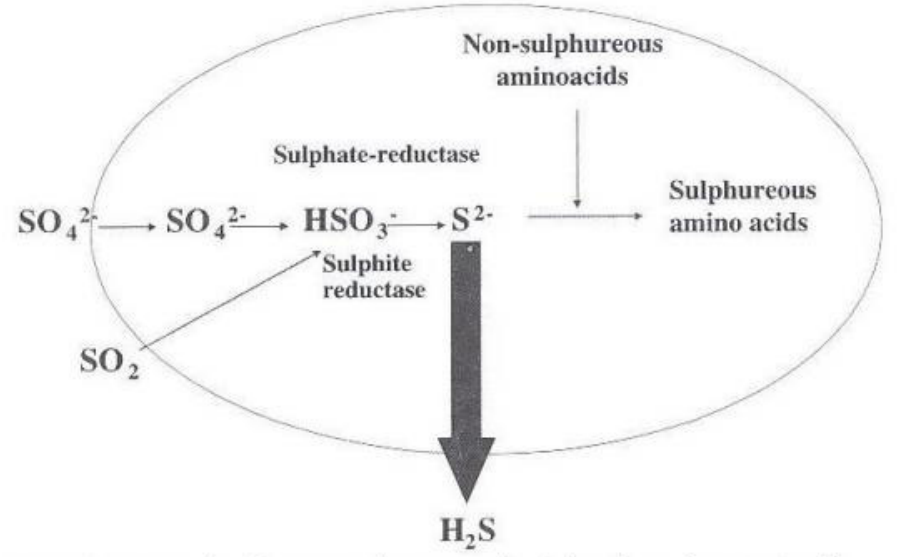

Figure 3: Interaction between nitrogen and sulphur in a wine yeast cell

In nitrogen-deficient musts, besides hydrogen sulphide generation, also the quantity of some superior alcohols increases significantly during the fermentation (Ough et al., 1980).

It is permitted to complement the nitrogen content of musts with the help of several ammonium salts, in particular, diammonium phosphate and yeast autolisates rich in organic nitrogen compounds.

The optimal time for nitrogen addition is 1-2 days after the fermentation has started. Nitrogen feeding suddenly increases the speed of fermentation, thus to provide smoother fermentation it can be postponed until about the beginning of the stacioner phase.

In accordance with the findings above, it is absolutely not indifferent when and how you complement the nitrogen content of musts. At the beginning of the fermentation it is essential to add not only inorganic $\mathrm{NH}_{4}{ }^{+}$salts but also amino acids as well as to know the amino acid composition of the must to be fermented.

Based on the above items, the objectives of our work will be summarized further on.

In the practical everyday life, the form and timing of adding fertilizers constitute a really significant wine quality and logistical issue. Fermentation stop results in further storage and wine handling problems.

Up till now, formol titration has been used most among the chemical methods to determine the assimilable nitrogen content of musts and wines. However, this method is quite slow and not precise enough, as it is characterised by quite a large spread.

The aim of our present work was to elaborate such a quick, easily applicable method that can be used for routinish measurements in the viticultural practice.

Furthermore, we completed our work with the determination of the proline content of musts and wines both to verify its constancy and to be able to draw conclusions on the originality of wines.
In the course of our present project

- we worked out a spectrophotometrical method to determine the assimilable nitrogen content

- we measured the assimilable nitrogen content of the same musts by formol titration and spectrophotometrially

- we measured the assimilable nitrogen content of this year's musts by formol titration

\section{Materials and methods}

For our measurements, we used musts from the trading production vintage of 2005 as well as musts deriving from other experiments of the department.

\section{Determination of the assimilable nitrogen content by formol titration}

We neutralize the organic acids of the must and the wine by $\mathrm{NaOH}$, until $\mathrm{pH}=8$. We oxygenate the $\mathrm{SO}_{2}$ of wines by $\mathrm{H}_{2} \mathrm{O}_{2}$ and then we bind the $\mathrm{NH}_{2}$ group of the -amino acids by formaldehyde and we titrate the carboxyl groups just released by $0.1 \mathrm{NaOH}$.

While constant stirring, we neutralize $50 \mathrm{~cm}^{3}$ must or wine by $\ln \mathrm{NaOH}$ solution to about $\mathrm{pH}=7.8$. Then we set the $\mathrm{pH}$ by $0.1 \mathrm{n} \mathrm{NaOH}$ to exactly 8 .

We add 2 drops of $\mathrm{H}_{2} \mathrm{O}_{2}$ and 1 or 2 minutes later $20 \mathrm{~cm}^{3}$ of formaldehyde. Then, after stirring it for 1-2 minutes, we titrate it by a $0.1 \mathrm{n} \mathrm{NaOH}$ solution to exactly $\mathrm{pH}=8.5$. We record the number of mls consumed of the $0.1 \mathrm{n}$ base.

Amino nitrogen $(\mathrm{mg} / \mathrm{l})=\mathrm{ml}^{*}$ factor $* 28$

\section{Determination of the assimilable nitrogen content by the spectrophotometrical method}

Reagents:

$3 \%$ ninhydrin

isopropanol (diluted with distilled water in the ratio of 1 tol)

Procedure:

We dilute the must or wine 10 times with distilled water. We take $0.5 \mathrm{ml}$ out of the diluted sample, then we add $1 \mathrm{ml}$ of ninhydrin solution and put it into a hot water bath for 15 minutes. We cool it back to room temperature and we add $5 \mathrm{ml}$ of isopropanol in the ration of 1 to 1 . After that we measure the absorbance of the sample at $570 \mathrm{nmn}$.

We showed the calibration plot using valine and we calculated the nitrogen content thereof.

$\mathrm{N}(\mathrm{mg} / \mathrm{l})=(28.08 * \mathrm{~A}-14.38) *$ dilution

\section{Results}

Comparison of the two measurement methods:

It is well visible on figure 4 that we got different results by the two different measurement methods. Of course, the 


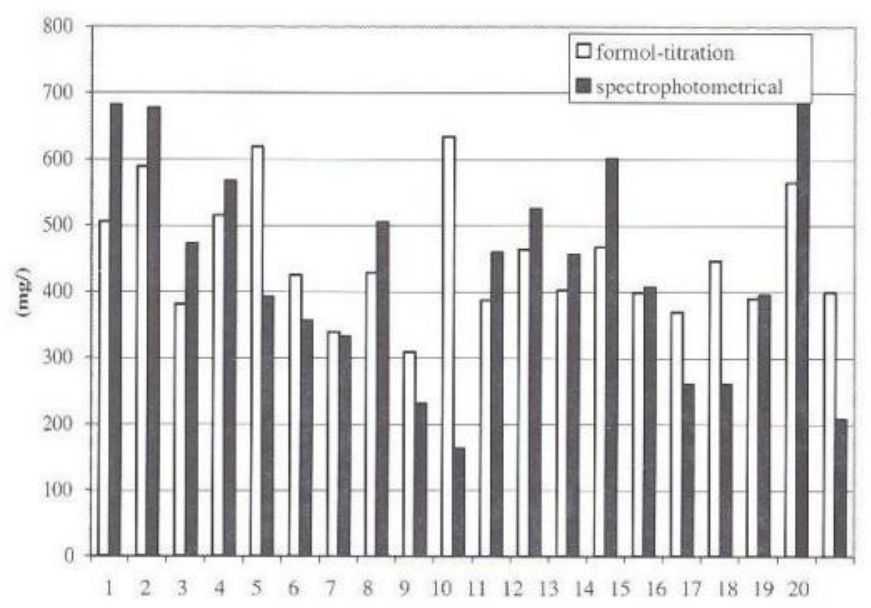

Figure 4: Comparsion of the two measurement methods

concentrations indicated are average values of measurements conducted in three parallel repetitions. Based on the measurement circumstances and the results, we can state that the spectrophotometrical measurement method is much more reliable and faster. Comparing the two methods we can state that the spread of formol titration is much bigger, i.e. $\mathrm{X} \pm 12 \%$, whereas the spread of the spectrophotometrical method is as little as $\mathrm{X} \pm 5 \%$.

After the comparison of the two measurement methods, besides the AFN-content of musts from the vintage of 2005 , we also determined the proline concentration.

\section{Determination of the AFN concentration of musts spectrophotometrically:}

Figure 5 illustrates the AFN- concentration of Kékfrankos musts. The assimilable nitrogen concentration well exceeded the value advised by the professional literature, i.e. minimum $200 \mathrm{mg} / \mathrm{l}$ in each sample.

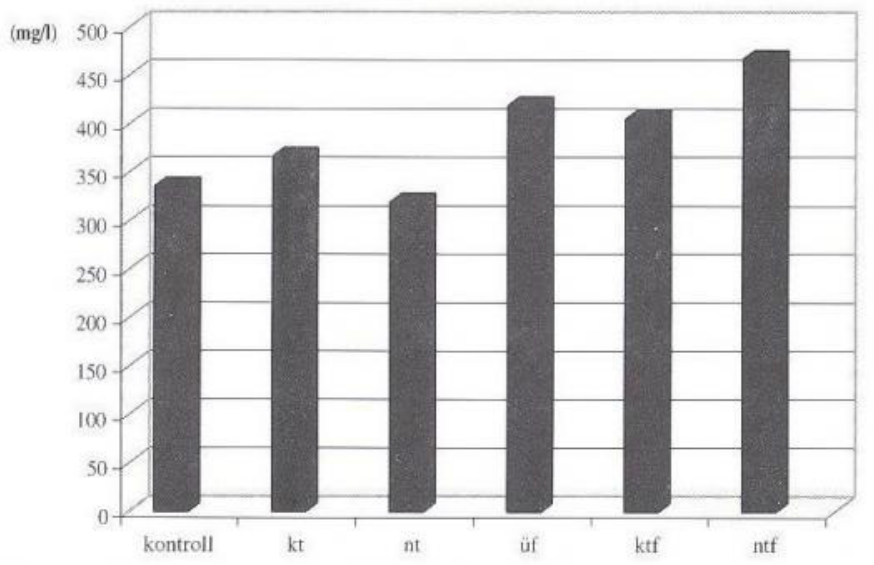

Figure 5: AFN-concentration of Kékfrankos musts

However, this tendency cannot be stated about Olaszrizling musts (Figure 6). In the vast majority of the samples, the AFN-content is just a bit above the critical threshold value, or is represented in an even smaller quantity in the samples. Thus, adding fertilizers by all means is recommended in each case.

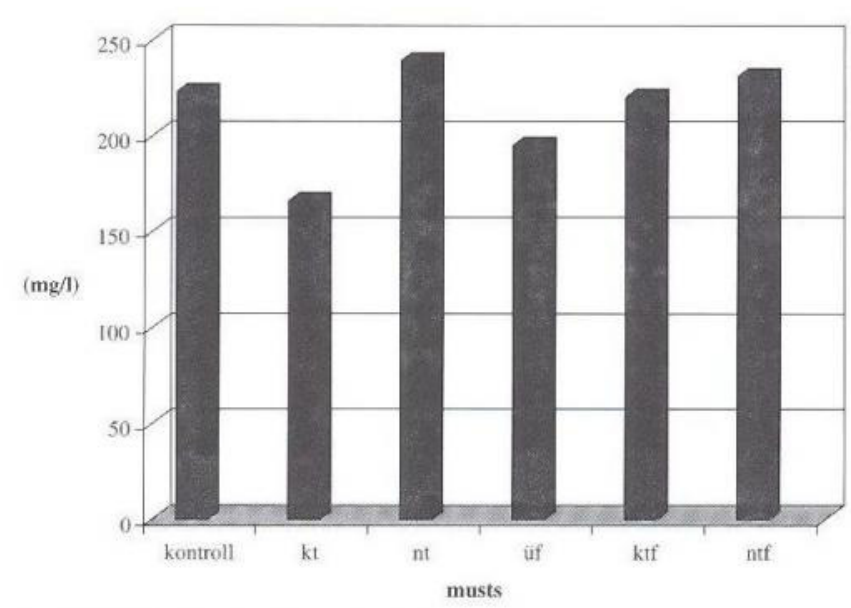

Figure 6: AFN-concentration of Olaszrizling

Of course, the amino nitrogen content of a given grapevine or must can be influenced by several factors (composition of the soil, the way of providing required nutriments, ripeness level of grapevine etc.), therefore we must conduct further tests to dissolve this anomaly.

Comparing the white and red grape musts, we can state that the AFN-content is clearly much higher in red grape samples. These results require and give rise to further research. (Figure 7)

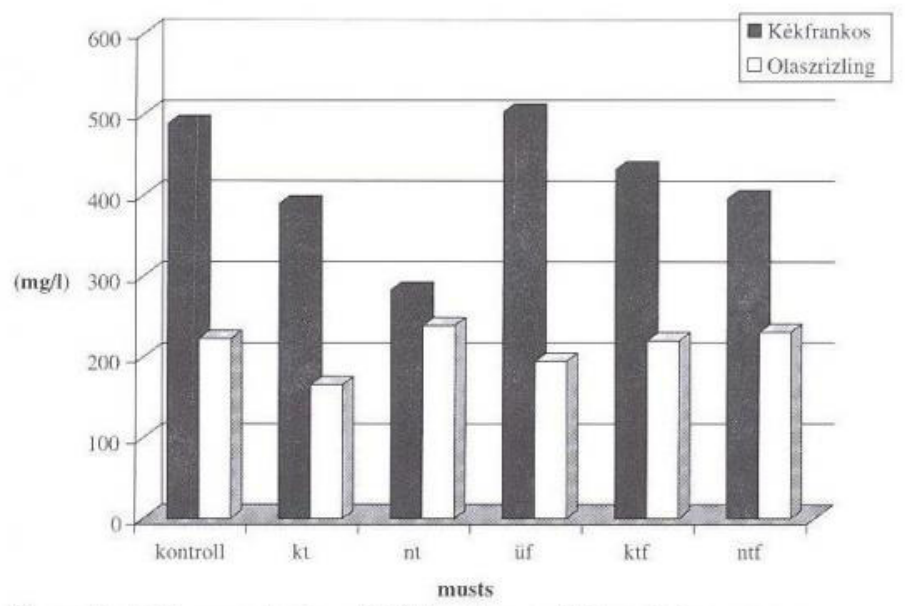

Figure 7: AFN-conentration of Kékfrankos and Olaszrilzing musts

\section{Ripening dynamic tests:}

In addition to musts, we also measured the AFN concentration in different grapevines while ripening. (Figure 8 )

In the course of ripening, the AFN-content shows a similar picture in each sample, that is, after a slightly increasing stage, a slightly decreasing trend can be observed. The Olaszrizling and Muscat Ottonel varieties contain assimilable nitrogen in a much lower quantity also here. The AFN-content of Olaszrizling changed in the range of 200 to $400 \mathrm{mg} / \mathrm{l}$ during the ripening period. It could be measured at a wider range in the Muscat Ottonel sample, where we measured their quantity between 200 and $600 \mathrm{mg} / \mathrm{l}$. The AFN-content of Cabernet Sauvignon well exceeded that of the two former ones: $500-700 \mathrm{mg} / \mathrm{l}$. 


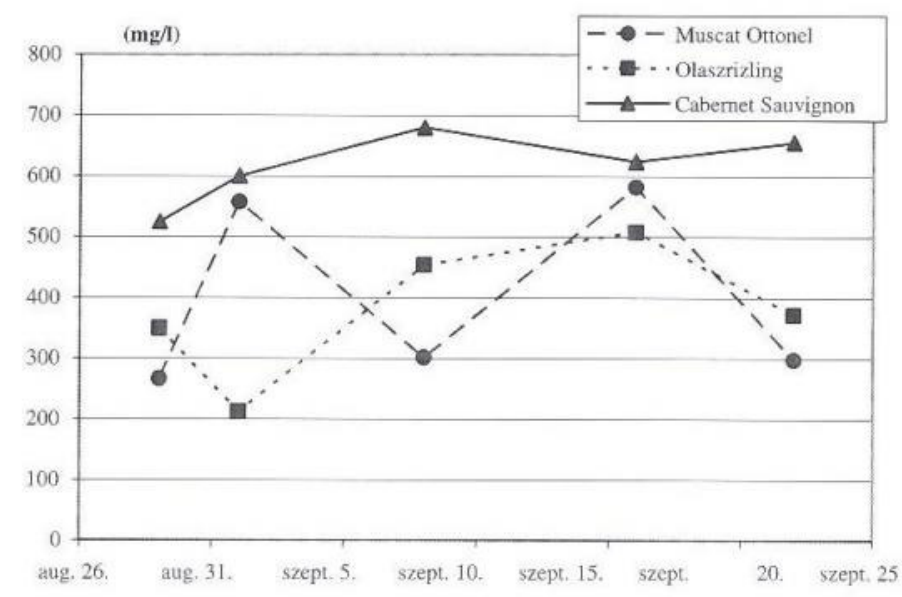

Figure 8: Ripeningdynamic tests

\section{Conclusion}

All things considered, we can state that there seems to be quite significant difference between the two measurement methods (formol titration and spectrophotometrical method). In the everyday life, we recommend the application of the spectrophotometrical measurement to determine the AFNcontent, as it is a much more reliable and faster measurement method than formol titration. According to the tendency observable in the case of white and red grapes samples, red grapes have a higher AFN-content.

\section{References}

Eperjesi I., Magyar I. \& Kállay M. (1998): Borászat Budapest, Mezőgazda Kiadó 547 p.

Kállay M., Ticozelli P. \& Szövényi E. (2004): A nitrogén és az oxigén szerepe az erjedésben Borászati Füzetek, 4: 15-20.

Henschke, P. \& Jiranek V. (1993): Yeasts-metabolism of nitrogen compounds. Wine microbiology and biotechnology ed, FLEET, G. H. Harwood Academic Publishers, Switzerland, 77-164.

Ough, C.S. \& Bell A.A. (1980): Effects of nitrogen fertilization on grapevineson aminoacids metabolism and higher alcohol formation during grape juice fermentation. Am. J. Enol. Vitic., 31: 122-123.

Sablayrolles, J. M.: (1996): Sluggis and stuck fermentations. Effectiveness of amminium nitrogen and oxigen addition Wien Wiss. 51: 147-151.

Vos, P.J.A. \& Gray R. S. (1979): The origin and control of hydrogen sulfide during fermentation of grape must. Am. J. Enol. Vitic., 30: 187-197. 